\title{
Direito penal da reparação: contribuição para um novo paradigma a partir do modelo restaurativo ${ }^{1}$
}

\section{Criminal Law of Reparation: contribution to a new paradigm from the restorative model}

\author{
Mário João Ferreira Monte* \\ Nestor Eduardo Araruna Santiago* \\ André Araújo Barbosa**
}

\section{Resumo}

Este trabalho tem como objetivo investigar a possibilidade de se utilizar um modelo que possa representar uma alternativa ou complementação à denominada justiça penal tradicional. Como uma primeira resposta, ainda de caráter provisório, procura-se trabalhar com a justiça restaurativa, ressaltando seus aspectos relevantes. Utilizando-se o método dedutivo, baseado em pesquisa bibliográfica, resulta-se na observação de que os modelos tradicional e restaurativo de realização de justiça penal são, na verdade, subsidiários entre si, de forma que o direito penal seja, também, restaurador, tendo-se em vista, ainda, a utilização racional do princípio da proporcionalidade.

Palavras-chave: Direito penal. Justiça restaurativa. Sistema penal integral. Proporcionalidade. Garantismo.

1 Este artigo tem como base o que foi escrito para ser publicado na Revista Criminalia, com o título "Diritto Penale Riparativo", do primeiro dos presentes autores, alterado agora tanto na forma como no conteúdo. Pretende-se, deste modo, o seu desenvolvimento, com outra visão, numa interlocução luso-brasileira, no âmbito do Projeto sobre Justiça Restaurativa, apoiado pela CAPES.

Possui Doutoramento Europeu em Ciências Jurídico-Criminais, pela Universidade de Navarra, com título homologado pela Universidade do Minho. Professor na Escola de Direito da Universidade do Minho. Guimarães - Portugal. E-mail: monte@ direito.uminho.pt

* Doutor em Direito pela Universidade Federal de Minas Gerais. Professor do Programa de Pós-Graduação em Direito Constitucional da Universidade de Fortaleza. Coordenador do Laboratório de Ciências Criminais da Universidade de Fortaleza (LACRIM). Professor do Curso de Direito da Universidade Federal do Ceará. Advogado Criminalista. Fortaleza - Ceará - Brasil. E-mail: nestorsantiago@gmail. com

*** Mestre em Direito Constitucional pela Universidade de Fortaleza (Unifor). Promotor de Justiça do Juizado Especial de Fortaleza. Pesquisador do Laboratório de Ciências Criminais da Universidade de Fortaleza. Fortaleza - Ceará - Brasil. E-mail: andrempe1@gmail.com 


\section{Abstract}

This paper proposes to investigate the existence, in the traditional justice system, of any model that can be used as an alternative or complement to the traditional criminal justice, which was humanized especially through the work of Beccaria. As a first, but temporary, measure, we work with restorative justice, highlighting relevant aspects. Using the deductive method, based on literature research, we observed that the traditional and restorative models of criminal justice are actually subsidiary to each other, so that the criminal law is also restorative, also considering the efficient use of the proportionality principle.

Keywords: Criminal Law. Restorative justice. Full penal system. Proportionality. Guaranteeism.

\section{Introdução}

Da análise da localização, da função e dos fins do direito penal resulta uma questão ligada ao problema dos seus limites: saber se existe algum modelo que se apresente como alternativo ou complemento ao que, aqui, pode ser designado por justiça penal tradicional. E das respostas possíveis, uma tem sido promovida por setores diversos, incluindo penalistas, quando não pelo legislador: a justiça restaurativa. É uma questão que se prende, sobretudo, com o princípio da subsidiariedade penal.

Diferentemente da Justiça Redistributiva, que hoje é o paradigma do direito penal de aplicação de sanções por intermédio do ajuizamento de ações penais e o seu julgamento por um juiz, a Justiça Restaurativa busca no diálogo entre os envolvidos no conflito penal - nomeadamente o autor do fato e a vítima - a solução para a questão.

Não se pretende, neste trabalho, analisar a fundo a justiça restaurativa. A intenção é apreciar criticamente os aspectos mais relevantes deste modelo, relacionando-os com o direito penal tradicional. A partir de uma análise dedutiva, baseada em pesquisa bibliográfica, resultará a demonstração de que a justiça restaurativa não sobrevive 
incólume às críticas que apelam à necessidade de os princípios penais corrigirem os modelos restaurativos. Mas, também, e sobretudo, resultará a necessidade de o direito penal acolher algumas das ideias restaurativas que, numa palavra, o tornem mais reparador.

\section{Subsidariedade penal, legalidade e justiça}

As ideias de Beccaria foram conquistas humanistas e humanizadoras do direito penal dos tempos modernos. Basta observar que, desde então, o sistema penal, baseado no critério da legalidade como limite de atuação do Estado, confere segurança e certeza aos cidadãos. Além disso, a intervenção penal estatal (ou estatal penal), para que seja legítima e faça valer, na prática, os critérios estabelecidos na lei escrita, deve adotar a subsidiariedade como ultima ratio do sistema, limitando os custos axiológicos da sua intervenção às situações onde indiscutivelmente se torna indispensável ${ }^{2}$ (DIAS, 2012, p. 128).

E não é só. Considerando que o Estado detém o monopólio da jurisdição penal, o princípio da proporcionalidade deve dirigir a atuação dos agentes encarregados da imposição de sanções, tornando claro que não há pena sem culpa e que esta será o limite da medida da pena, e que as penas impostas devem ter utilidade para o equilíbrio na vida em sociedade e viabilizar a reinserção social do delinquente.

Assim, a perspectiva de realização integral da justiça penal (MONTE, 2008), num complemento de funções do direito e do processo penal, dá-se não só pelo respeito às diretrizes e valores estabelecidos por um Estado, mas, também aos próprios princípios garantistas que Ferrajoli (2002) estabeleceu, como reforço de realização do princípio da dignidade da pessoa humana. ${ }^{3}$

\footnotetext{
2 Como diz Dias (2012, p. 128), a intervenção penal tem de ser "absolutamente indispensável à livre realização da personalidade de cada um na comunidade".

3 É certo que as referências de Ferrajoli (2002) para a elaboração dos princípios garantistas têm como base a realidade italiana. Contudo, é inegável que seus ensinamentos também se aplicam de forma direta à realidade brasileira, que também prevê no seu texto constitucional o respeito à dignidade humana como um dos pilares da República Federativa.
} 
Note-se também que a subsidiariedade penal, que se afirma, desde logo, pela circunstância de nem a todos os comportamentos socialmente censuráveis corresponder uma pena, não resolve o problema de todos os casos em que ainda existe dignidade penal, mas não claramente, necessidade de uma pena. Esta segunda asserção nem sempre encontra no direito penal resposta adequada. A solução está, na maioria das vezes, nas respostas parapenais ou extrapenais, importando saber, no entanto, se essas são também as mais adequadas. Mas, mais do que isso, não vale a pena iludir que, mesmo quando se afirma a dignidade e a necessidade penais, a justiça concreta do caso encontra não raras vezes refúgio nas causas de exclusão de culpa ou de ilicitude ou ainda, quando isso não é possível, na dispensa ou suspensão da sanção. Sabese que estas soluções, embora certeiras do ponto de vista dogmático, e explicadas por razões político-criminais, podem não ser razoáveis em termos de justiça material do caso concreto. $\mathrm{E}$, por isso, um critério que dê sentido de justiça ao conflito pode ser indispensável. A resolução do problema, aqui, passa, por exemplo, por saber se a introdução do acordo, da concertação entre os sujeitos processuais, poderá atingir esse objetivo.

E dizer isso é questionar mesmo a noção de proporcionalidade. Que ela valha como limite, no sentido de que a pena não deve ultrapassar a medida da culpa, parece indiscutível; menos consensual, no entanto, mas igualmente pertinente, é saber se a pena pode ser desproporcionalmente mais baixa que as exigências da culpa, do princípio da legalidade e, ao invés, responder a outro tipo de exigências. Dir-se-á que isso já sucede assim, na medida em que exigências de prevenção permitem uma medida da pena diferente daquela que a culpa sugere. Mas também é verdade que essa medida da pena, ditada por razões preventivas, está condicionada por um máximo e um mínimo ditados pela culpa. A questão é a de saber se esta pena, assim, não será igualmente injusta por não atender a outras exigências que a atirariam para outros limites ou até outros tipos de sanção. E, mais uma vez, a sanção obtida por acordo pode bem servir de exemplo. Deste modo, 
ressalta a questão de saber se o direito penal da prevenção - e por isso não apenas exclusivamente punitivo - é suficientemente justo.

Além disso, sempre se deverá questionar se os fins normalmente preconizados pelo sistema para as penas são verdadeiramente atingidos com as sanções que efetivamente são aplicadas. Ora, não é necessário ir muito longe para saber que as duas penas normalmente utilizadas - a prisão e a multa - estão longe de atingirem as finalidades a que estão pressupostas quando são aplicadas.

O direito penal representa a mais severa intervenção nos direitos fundamentais, sendo necessárias salvaguardas para garantir que não haja a violação indevida desses direitos e que seja assegurada a condição de ser humano do infrator. Nesse sentido, Mello (2010, p. 67) considera que qualquer intervenção penal que atinja de forma desarrazoada os direitos fundamentais inerentes à dignidade humana deve ser considerada inconstitucional. Por isso é que é necessário estabelecer limites ao exercício do poder punitivo. Não é por acaso que os princípios penais se relacionam intrinsecamente à ideia de dignidade humana.

De igual modo, o monopólio da jurisdição penal, associado ao princípio republicano, deveria realizar o Estado de Direito, garantindo a todos o acesso igual à justiça penal e a todos as mesmas condições de realização da justiça, o que não se verifica na prática em países como o Brasil. Este monopólio também não tem assegurado adequadamente o papel que os intervenientes no conflito podiam e deviam ter no processo. Importa saber se uma maior participação dos contendentes na resolução do conflito não tornaria a solução mais justa. E, sendo assim, é imperioso saber se o processo penal é suficientemente eficaz para garantir esta participação. Pode-se dizer que já existem espaços de consenso e de oportunidade que potenciam a participação dos vários sujeitos processuais no Brasil, como é o caso da transação penal, em casos submetidos aos Juizados Especiais Criminais; ou, então, o expediente de suspensão condicional do processo, aplicável, regra geral, aos crimes cuja pena mínima não seja superior a um ano. O problema é que esses 
espaços podem ser apenas de concordância, quando do que se trata é de saber se não podem ser de verdadeiro acordo. Naturalmente que, ao dizer isso, imediatamente acode a ideia de certo déficit de participação da vítima no processo penal, notadamente em razão de um modelo de obrigatoriedade da ação penal que dificulta esta intervenção.

O poder público, como ressaltam Pablos de Molina e Gomes (2012, p. 71), orienta a resposta oficial para uma perspectiva de castigo do ofensor, ficando a vítima desamparada, sem que sequer os interesses reparatórios desta sejam priorizados. A consequência da lógica do sistema é claramente negativa tanto pelo lado do ofensor como da vítima. Aquele considera que seu único interlocutor é o Estado, representado pelas instâncias judiciais. A situação do ofendido, muitas vezes escolhido aleatoriamente, é a ele desconhecida. Logo, não há como ter a mínima consciência da sua conduta em cotejo às consequências geradas à vítima. Esta, por outro lado, também não se sente representada pelas instâncias judiciais. Acaba por perceber o desinteresse e o espírito burocrático do sistema e "tem a impressão, nem sempre infundada, de atuar como mero pretexto da investigação processual, isto é, como objeto e não como sujeito de direitos" (PABLOS DE MOLINA; GOMES, 2012, p. 72).

Zaffaroni (2001, p. 183) aponta que a necessidade de racionalização do sistema faz com que a intervenção judicial acabe por perder o contato com a realidade, sem possibilidade de alcançar o conflito subjacente. No complexo mundo pós-moderno, Garland (2008, p. 430) adverte que o Estado deve compartilhar poderes com outras instituições e com a comunidade para solucionar os conflitos existentes.

Em poucas palavras: o desafio que se coloca ao direito penal da ilustração é o de saber se não pode ser mais justo e democrático, ampliando a sua percepção e resolutividade para questões subjacentes ao processo, mas que acabam condicionando o fato delituoso. Mais justo não significa a sua superação. Porque se assim fosse, a pergunta seria outra: se não pode ser simplesmente justo. 


\section{0 contributo da justiça restaurativa}

Voltem-se, agora, as atenções para a justiça restaurativa. Quando se procura um sentido para esse modelo, invariavelmente, este costuma ser apresentado como essencialmente justo, no sentido que assenta toda a sua razão de ser no princípio da justiça. Com a justiça restaurativa, busca-se, essencialmente, a justiça do caso concreto. E a justiça do caso é encontrada - segundo os cultores deste modelo - quando a sanção, atingida por acordo, é aquela que infrator e vítima querem. O ponto de Arquimedes é aquele que a vítima e o infrator determinam.

Segundo Santos (2009, p. 213), só a partir dos anos 1990 o tema justiça restaurativa começou a suscitar mais entusiasmo, apesar de que o termo e as experiências datam da década de 1970. Independentemente do momento em que tenha surgido, a Justiça Restaurativa, por intermédio de práticas restaurativas, é redirecionar o foco do culpado e da violação das leis para a reparação dos danos, o atendimento das necessidades e o envolvimento da comunidade no processo (YAZBEK; TRIGO, 2007, p. 29), já que ela é parte afetada pelo dano, ou, então, como apoiadora ou o outro na relação social frente a quem se responsabilizam e com quem se comprometem com os acordos construídos (YAZBEK; TRIGO, 2007, p. 30). Inexiste um procedimento único para a realização e aplicação de técnicas restaurativas, e, do ponto de vista da qualidade do resultado, isso é o que menos interessa, desde que sejam observados os princípios restaurativos sugeridos por Howard Zehr (2012). ${ }^{4}$

Santos (2009) sublinha o embate doutrinal no Brasil sobre a justiça restaurativa: enquanto o discurso criminológico da direita justiceira a associa a uma escandalosa tolerância face ao crime, as

No Brasil, há Projeto de Lei datado de 2006 (PLC 7006/2006, BRASIL, 2015, on-line) que prevê a introdução da Justiça Restaurativa como um microssistema auxiliar ao sistema penal tradicional. Entretanto, o texto, que mais se assemelha a uma carta de intenções, padece de lacunas e conceitos jurídicos indeterminados, que fazem com que sua promulgação, tal como está, seja absolutamente inócuo para modificar o estado atual de tratamento da questão penal, ficando sujeito à livre interpretação dos operadores jurídicos que porventura venham a aplicá-lo. 
escolas criminológicas de esquerda preocupam-se com o fato de que as práticas restaurativas possam conduzir a uma subreptícia expansão do controle penal sobre o cidadão. Assim, para ela, importa perguntar se há especificidades na realidade criminal brasileira que condicionem de forma decisiva a admissibilidade e a conveniência da implantação de práticas restaurativas. Aponta, também, que existem entendimentos divergentes sobre aquilo que a proposta restaurativa deve ser e as práticas restaurativas que já existem em outras partes do globo, que assumem características diversas. Segundo ela, "ninguém sabe com exactidão isenta de dúvida nem o que é a justiça restaurativa nem qual é a realidade criminal brasileira. Sobre aquela, abundam as propostas de definição mais díspares. Sobre esta, inexistem dados empíricos completos e atuais" (SANTOS, 2009, p. 213).

Por isso, há quem entenda que a justiça restaurativa deve funcionar como um modelo alternativo e paralelo ao da justiça tradicional - como que respondendo positivamente às correntes abolicionistas do direito penal, mas com uma resposta concreta, pós-moderna, superando as fragilidades do sistema tradicional, moderno - ou, pelo menos, complementar, mas ainda assim distinto - como que corrigindo as imperfeições que o sistema tradicional manifesta, todavia, sem superálo. Contudo, Sica (2009, p. 412) adverte que a importação e idolatria das soluções consensuais na América Latina deve ser precedida de aguda reflexão, a fim de se evitar distorções de natureza conceitual.

É inegável que a implantação de modelo restaurativo deve levar em conta o contexto da sociedade brasileira atual, onde o discurso midiático ressoa forte numa ode ao encarceramento como solução para o problema da criminalidade, particularmente aquela comum nas classes mais desfavorecidas economicamente. Daí que a implantação da justiça restaurativa no Brasil deve ser cuidadosa, precedida de uma estrutura adequada e de uma conscientização sobre as suas potencialidades para solucionar certos tipos de conflitos. Não pode ser vendida como o milagre da solução para o problema da violência e da grande criminalidade. Deve ser implementada como uma proposta de, para determinados tipos de conflitos com repercussão penal, olhar para 
as relações sociais a partir de um novo prisma, cuja base seja o diálogo e o consenso, que represente a expectativa de diminuir a indiferença, o rancor e a mágoa que permeiam as relações sociais e desembocam em diversos conflitos (SOUZA; FABENI, 2013, p.156).

Dessa forma, justiça tradicional e justiça restaurativa são dois modelos essencialmente distintos. Para nós, no entanto, o desafio que se coloca é o de restaurar o direito penal, no sentido de penetrá-lo com ideias essencialmente restaurativas. Partindo do melhor que a justiça restaurativa oferece, sem deixar de assestar a este modelo inegáveis fragilidades, não se vê por que não possa aprimorar-se o sistema de justiça penal à luz do paradigma restaurativo.

Dito isto, percebe-se que o posicionamento, face ao direito penal, há de ser o de conjugar o princípio da legalidade, a fundamentação constitucional da tipificação penal, com o princípio de justiça. 0 que significa à partida uma fundamentação do direito penal de tipo metaconstitucional.

$E$, se relativamente à sua fundamentação há de ser como se acaba de apontar, quanto às suas finalidades, o direito penal deve ser essencialmente reparador. Reparador em um sentido mais amplo que englobe, como enunciam David Miers et al. (2001, p.9), "Responsibility, Restoration and Reintegrations" (responsabilidade, restauração e reintegração). Seus objetivos mais particulares incluem a prevenção de reincidência, o reconhecimento do interesse da vítima, a admissão do ofensor pelo dano causado, o interesse da comunidade na reabilitação do infrator e, consequentemente, uma redução nos custos da justiça criminal.

A reparação, conseguida através de um processo que envolva a vítima e o infrator, deve estar na mira do direito penal.

Ressalta da justiça restaurativa uma pretensão de efetiva justiça do caso concreto, ao ponto de se conseguir uma verdadeira pacificação das pessoas envolvidas e destas com a comunidade. Por isso, não está em causa apenas a atribuição de responsabilidade, v.g., penal, muito 
menos de culpa, mas a realização da justiça que se concretiza num certo tipo de processo diferente do tradicional. Monte (2014, p.103) lapida essa nova perspectiva ao ressaltar que "mais do que a solução final, mais do que a sanção acordada, no cumprimento dos fins das penas estará o processo que leva a essa sanção". Ele aponta que o processo que coloca vítima e agente, frente a frente, dialogando, assumindo conscientemente responsabilidades, implica uma filosofia distinta para a compreensão do fenômeno criminógeno e sua resolução. Na medida em que se atribui à vítima um papel que normalmente não tem e que se visa um acordo, uma concertação entre infrator e vítima, com ou sem a intervenção da comunidade e/ou de um mediador, mais do que a integração do caso num tipo legal de crime, satisfaz-se assim exigências do princípio da legalidade e das finalidades penais.

O processo com vista ao acordo, colocando frente a frente vítima e infrator, permitindo àquela obter a reparação dos seus danos patrimoniais e não patrimoniais, numa palavra, danos do crime - e a este assumir voluntariamente a responsabilidade pelo crime, possibilitando a sua reintegração, implica seguramente uma distinta compreensão e resolução do fenómeno criminógeno.

Isso é importante? Sem dúvida que sim. Isso não se alcança na justiça penal tradicional? É sabido que, na justiça tradicional, reconhecendo-se que o infrator realizou o crime tipificado na lei obedecendo ao princípio da legalidade - e aplicando-se uma pena igualmente tipificada legalmente, nem sempre se alcança esse sentido de justiça. Quantas vezes se declara culpado um infrator, aplica-se uma pena de prisão, mas suspende-se a pena ou se aplica um regime prisional incompatível com a repercussão social do fato, sem que a vítima ou a comunidade compreendam a razão desta suspensão. Não que essas soluções sejam desprovidas de sentido de justiça e muito menos ilegais. O problema é que se gera um sentimento de injustiça, por incompreensão, acompanhado de um sentimento de impunidade e de insegurança. Pode-se dizer que é, sobretudo, um problema comunicacional. Sem dúvida, mas que desnuda alguma fragilidade do sistema penal tradicional. 
Normalmente, na justiça penal tradicional, quando existem espaços de consenso, existe alguém que propõe uma sanção, dentro do que o tipo legal permite, e alguém que aceita. Não existe paridade. Um tem o poder de propor e o outro tem a faculdade de aceitar ou não. Não se trata ali de um dever, nem sequer de um direito subjetivo; tratase de um poder, conferido pela Lei, um poder de auctoritas, do Estado. Até porque, normalmente, quem propõe é um representante do Estado - o Ministério Público, tal como acontece nos procedimentos realizados perante os Juizados Especiais Criminais. Esse também foi o modelo adotado no Projeto de Lei do novo Código de Processo Penal.

$\mathrm{Na}$ justiça restaurativa, diferentemente, ambos têm o direito de propor e de aceitar ou não. Também aqui não se trata de um dever de propor nem de aceitar. O processo, assentando basicamente na voluntariedade dos sujeitos, não pode implicar qualquer dever de acordo. Trata-se de exercer um direito de acordar com outrem. Tratase de uma situação, pelo menos formalmente, paritária. Mas, sendo assim, o processo de acordo é já um processo de reparação. Não serão necessárias explicações para se compreender que os sujeitos arrancam da catarse do crime e dos seus efeitos uma solução jurídica, que refletirá esse efeito reparador, mas o processo, em si, é também reparador. Por isso, quer se acentuem os méritos do processo, quer se enalteçam as virtualidades da sanção, a verdade é que uma e outra coisa são dois lados de uma mesma realidade: a justa reparação. Por justa reparação há de entender-se não só a reparação civil dos danos causados à vítima, mas aquela que respeita a dignidade da pessoa do acusado. E isso só é possível num processo próprio, restaurativo, que atenda às exigências do caso concreto.

Dito isto, percebe-se que a justiça restaurativa introduz dois elementos que se complementam e que a caracterizam: a reparação - elemento que há de relevar para o direito substantivo - e a justiça do caso - elemento que há de relevar do lado do processo.

Pode-se perguntar se isso será exagerado, ou se será um desvio significativo do direito penal tradicional, inconciliável com os princípios que o norteiam. 
Sem prescindir do princípio da legalidade penal, pode com segurança, hoje, dizer-se que o juiz não é necessariamente a boca da lei. Não o é no sentido de que se não limita a uma aplicação subsuntiva e acrítica da lei; não o é, porque ao juiz, atualmente, reconhece-se um papel cocriador do Direito, desde que não o faça de forma "ativista". Fala-se a esse propósito de "função 'criadora' da jurisprudência" (DIAS, 1974, p. 47). Não no sentido de uma criação pessoal do direito pelo juiz, solipsista, mas como "um 'desenvolvimento normativo' das regras substantivas aplicáveis, uma verdadeira 'criação' jurídica relativamente ao caso sub judice, mesmo nas hipóteses em que formalmente a decisão aparece como mera conclusão silogística das premissas legais" (DIAS, 1974, p. 48). É essa atitude do juiz, como sujeito cocriador do direito, que se manifesta no momento da judicativa decisão do caso concreto, que o afasta da atividade de mera aplicação acrítica do direito escrito.

$\mathrm{E}$, como é evidente, isso só é possível admitir-se hoje porque se assinala ao processo penal um papel que é, não apenas meramente instrumental, de aplicação das normas substantivas, mas, ainda que reconhecendo uma relação de mútua complementaridade com o direito penal, de alguma autonomia teleológica que permite encontrar soluções, não contrárias às regras substantivas, mas que, transcendendo-as no sentido de maior justiça, procurem a solução mais justa do caso concreto.

Como se vê, não se trata de romper com o direito escrito, prévio, não se trata sequer de reduzir o valor do princípio da legalidade. Tratase, ao invés, de elevar as suas potencialidades, dando-lhe, no caso concreto, um sentido de justiça mais apurado que o legislador, na norma escrita, não podia ter dado.

\section{Um novo desafio: "restaurar" o direito penal}

À pergunta feita, no entanto, ainda não se deu resposta. Pode um maior sentido de justiça ser alcançado através do direito penal e do direito processual penal tradicionais, numa palavra, através da justiça penal tradicional? 
Sabe-se que o processo penal, apesar dos espaços de consenso que já comporta, apresenta limites de difícil superação nesta necessidade de transcendência judicial. Por muito que se pretenda assestar uma função criadora do direito ao juiz, este não pode ir além do que o direito penal impõe e o processo penal permite. Hodiernamente, certo que já se encontrou no direito penal e no direito processual penal de tipo europeu continental uma certa abertura no sentido da consagração de espaços de consenso. Mas muito longe, por certo, do que é tradicional no direito anglo-saxônico. Esses espaços são na sua maioria, ainda, de concordância, e não propriamente de acordo, de concertação. E, por isso, estão ainda muito longe do que pode ser feito. No Brasil, em especial, a lei ressalta de forma clara que deve haver concordância, embora se fale em conciliação.

Que contribuição pode o paradigma da justiça restaurativa oferecer nesta matéria? Trata-se de um modelo que, na sua essência, privilegia os espaços de concertação, de efetivo acordo, e não apenas de concordância. Potencializa a justiça do caso, mas não significa a privatização do conflito, devendo o Estado supervisionar o processo de mediação e o resultado do acordo, evitando soluções que desvirtuem a finalidade do paradigma e contrariem princípios constitucionais basilares. Não é esse o espaço para entrar em maiores considerações, mas não custa reconhecer que 0 direito penal da ilustração ${ }^{5}$ põe limites à negociação de certos valores considerados indispensáveis à convivência social. Por isso se compreende que não se pode deixar a tutela de bens jurídico-penais nas mãos dos entes privados, sob pena de o direito penal deixar de desempenhar o seu papel. A concertação no âmbito do conflito penal só pode ter lugar quando, por um lado, o Estado não deixa de desempenhar o seu papel de administrador da justiça penal e quando, por outro, permitir que, na decisão do caso concreto, a solução seja mais justa que injusta.

5 Mesmo que se partisse do direito natural, chegar-se-ia à mesma conclusão. 
E, na nossa concepção de justiça restaurativa, terá de ser assim, porque se não prescinde, ou pelo menos não se deve prescindir, de que a última palavra seja dada por uma autoridade judiciária. As partes podem fazer o esforço de concertação, podem até entender que a solução a que chegam é a mais justa. Mas será uma entidade judiciária que deverá avaliar se ela é adequada para os fins restaurativos e para a proteção da dignidade humana. E, aqui, para nós, não pode haver lugar ao irredutível retorno ao princípio da legalidade de sentido positivista. Porque aqui, se existe espaço à reparação, a pena deve ser a mais justa, mesmo que não seja a legalmente imposta. Só assim se compreende o sentido do modelo restaurativo, mas sem que isso, por seu turno, implique afastar-se do modelo garantista, pois as soluções inerentes à concertação terão seus limites na lei.

Nesse sentido, a lei penal continuará a ser aplicada, pois que o fato praticado há de ser considerado criminoso pela lei penal positiva. Mas a solução do caso pode transcender a solução que o legislador teria encontrado se a justiça restaurativa não existisse como solução. Pode transcender-se por homenagem ao princípio de justiça que, todavia, deve ser homologado por uma entidade judiciária para se evitar, por um lado, a privatização do conflito e, por outro, a aplicação de sanções injustas.

Trata-se, também, de dar outro conteúdo ao princípio da proporcionalidade e de encarar o princípio da culpa apenas como pressuposto e não como fundamento da punição. Sem dúvida. Mas não se vê que haja algum problema em questionar o princípio da proporcionalidade se daqui resultar maior justiça na resolução do caso concreto. Posto é que esse questionamento produza uma maior eficácia na aplicação da justiça penal. Não é esse o espaço para desenvolver tal assunto, mas cremos que a justiça restaurativa pode ajudar a questionar este tópico no seio do próprio direito penal.

E veja-se que o papel desse modelo restaurativo pode ser imenso. Pense-se que os casos sujeitos à justiça restaurativa não têm de ser necessariamente os menos graves. Podem ser de gravidade 
maior (MONTE, 2012), casos em que, necessariamente, se discutem verdadeiramente os limites do direito penal positivo e onde se joga o princípio da subsidiariedade penal. Por exemplo, que maior conflito pode enfrentar-se do que saber se deve punir-se um índio, porque enterrou vivo seu filho que nasceu com deficiência? Que deve fazer o Estado: deixar de punir, respeitando as convicções culturais, étnicas, dos infratores ou deve punir, sabendo que uma tal punição não alcança as finalidades das penas?

Não será difícil perceber que a justiça restaurativa poderia constituir uma solução adequada para esse tipo de problemas. Nela, a dimensão axiológica claramente sobrepõe-se à normativa; nela, o conflito pode ser resolvido atendendo às exigências do caso concreto, através de soluções adequadas, evitando propostas que, apesar de legais, sejam manifestamente injustas ou incompreensíveis. Afinal, a justiça restaurativa é sobretudo uma solução interrelacional e, por isso, intercultural.

Só que, se assim pode ser, não vemos porque o direito penal não possa comportar uma tal dimensão restaurativa. Evitar-se-ia, em casos como os de crimes de motivação cultural, recorrer a expedientes dogmáticos, legais ${ }^{6}$, e que, contudo, poderão não constituir a solução mais justa do caso. Um direito penal da reparação seguramente que

6 Sem admitir o recuo do direito penal frente a condutas culturalmente motivadas, mas igualmente censuráveis, porque atentatórias de bens jurídicos, sempre se poderia recorrer a todo um leque de soluções dogmáticas: por exemplo, o recurso ao conceito de ação socialmente adequada, do consentimento, do exercício de direitos, como o direito à cultura, ou da exclusão da culpa, ou ainda o recurso ao erro sobre a ilicitude que poderia ser apresentado como fenómeno susceptível de afastar a culpa, ou até de um erro de compreensão culturalmente condicionado, ou mesmo de um estado de necessidade desculpante. E, mesmo que a conduta tivesse de ser punida, não estaria arredada a possibilidade de atenuação especial da pena. Tudo ou quase tudo acabaria por ser considerado adequado, justificado, desculpabilizado, numa palavra, jurídico-penalmente "compreendido". Até porque, concordando neste ponto com Silva Dias (1996, p. 59), duas dificuldades relevantes são apontadas: "a norma legal vê afectada a sua facticidade pelo costume contrário e padecerá normalmente de um elevado índice de ineficácia, integrando o âmbito da chamada 'legislação simbólica'; por outro lado, a afirmação da prevalência da lei [...] não significa ainda a punibilidade de todos os comportamentos praticados ao abrigo das regras costumeiras, pois para tal é necessário atribuir o facto ao autor como obra sua de acordo com os critérios da imputação jurídico-penal”. 
permitiria outro tipo de abordagem e de resolução desse tipo de caso. É evidente que nem todos os crimes encontram melhor solução através do modelo restaurativo. Porém, mesmo aqueles que não cabem ou não são adequados para um processo tipicamente restaurativo, podem ter na justiça tradicional uma resolutividade melhor se algumas práticas restaurativas forem utilizadas.

\section{Reflexão conclusiva}

Feitas essas reflexões, algumas conclusões podem extrair-se: por um lado, a necessidade de temperar o princípio da legalidade penal com o princípio de justiça; por outro, a necessidade de uma visão metaconstitucional do direito penal, que não dispensa a referência axiológico-normativa da Constituição para o legislador penal, mas que se não reduz a ela para fundamentar a justiça penal. E, finalmente, tanto nas finalidades penais - que além das exigências da culpa e da prevenção, devem responder a necessidades de reparação - como no processo - que, começando por privilegiar uma função criadora do direito por parte do juiz, pode levar a espaços de consenso, de acordo, que não apenas de concordância - pode e deve aprofundar-se o sentido reparador que o próprio direito penal deve perseguir.

Se tudo isso tiver resultado destas considerações postas pelo modelo de justiça restaurativa, então diríamos que do que se trata é de arrancar desse modelo de justiça e interpelar o próprio modelo de justiça penal tradicional, no sentido de uma "restauração" do direito penal.

\section{Referências}

BRASIL. Projeto de Lei (PLC) n 7006, de 10 de junho de 2006. Propõe alterações no Decreto-Lei $n^{\circ} 2.848$, de 7 de dezembro de 1940, do Decreto-Lei $n^{\circ} 3.689$, de 3 de outubro de 1941, e da Lei $n^{\circ}$ 9.099, de 26 de setembro de 1995, para facultar o uso de procedimentos de Justiça Restaurativa no sistema de justiça criminal, em casos de crimes e contravenções penais. 2006. Disponível em: <http://www.camara.gov. 
br/proposicoesWeb/fichadetramitacao?idProposicao=323785>. Acesso em: 20 abr. 2015.

DIAS, Jorge de Figueiredo. Direito penal: parte geral. Coimbra: Coimbra editora, 2012. v. I.

. Direito processual penal. Coimbra: Coimbra editora, 1974. v. I.

DIAS, Augusto Silva. Problemas do direito penal numa sociedade multicultural: o chamado infanticídio ritual na Guiné-Bissau. Revista Portuguesa de Ciência Criminal, Lisboa, ano 6, v. 2, p. 215- 237, abr./ jun. 1996.

FERRAJOLI, Luigi. Direito e razão: teoria do garantismo penal. São Paulo: Revista dos Tribunais, 2002.

GARLAND, David. A cultura do controle e ordem social na sociedade contemporânea. Tradução André Nascimento. Rio de Janeiro: Revan, 2008.

MELLO, Sebástian Borges de Albuquerque. O conceito material de culpabilidade: o fundamento da imposição da pena a um indivíduo concreto em face da dignidade da pessoa humana. Salvador: JusPodivm, 2010.

MIERS, David et al. An exploratory evaluation of restorative justice schemes. Londres: Home Office, 2001. Disponível em: < http://www. ibarji.org/docs/miers.pdf>. Acesso em: 22 jan. 2015.

MONTE, Mário João Ferreira. Da realização integral do direito penal. In: DIAS, Jorge de Figueiredo et al (Org.). Ars Ivdicandi: studos em homenagem ao Prof. Doutor António Castanheira Neves. Coimbra: Coimbra editora, 2008. p. 737-771.

Multiculturalismo e tutela penal: uma proposta de justiça restaurativa. In: BELEZA, Teresa Pizarro; CAEIRO, Pedro; PINTO, Frederico de Lacerda da Costa. (Org.). Multiculturalismo e direito penal. Coimbra: Almedina, 2014. p. 97-113. 
PABLOS DE MOLINA-Antônio Garcia; GOMES, Luiz Flávio. Criminologia. Tradução Luiz Flávio Gomes, Yellbuin Morote García e Davi Tangerino. 8. ed. São Paulo: Revista dos Tribunais, 2012.

SANTOS, Cláudia Cruz. A proposta restaurativa em face da realidade criminal brasileira. Revista Brasileira de Ciências Criminais, São Paulo, ano XX, n. 91, p. 209-229, 2009.

SICA, Leonardo. Bases para o modelo brasileiro de justiça restaurativa. De Jure: Revista Jurídica do Ministério Público do Estado de Minas Gerais, Belo Horizonte, n. 12, p. 411-447, jan./jun. 2009.

SOUZA, Luanna Tomaz; FABENI, Lorena Santiago. Dos juizados especiais criminais à justiça restaurativa: a justiça consensual no Brasil. Lex Humana, Petrópolis, v. 5, n. 1, p. 136-159, 2013.

YAZBEK, Vania; TRIGO, Maria Helena Bueno. Mediação transformativa e justiça restaurativa. Nova perspectiva sistêmica, São Paulo, v. 15, n. 28, p. 27-33, jul. 2007.

ZAFFARONI, Eugenio Raúl. Em busca das penas perdidas: a perda de legitimidade do sistema penal. Tradução Vania Romano Pedrosa e Almir Lopez da Conceição. 5. ed. Rio de Janeiro: Revan, 2001.

ZEHR, Howard. Justiça restaurativa. São Paulo: Palas Athena, 2012.

Recebido em: 18/06/2015

Aprovado em: 29/09/2015 